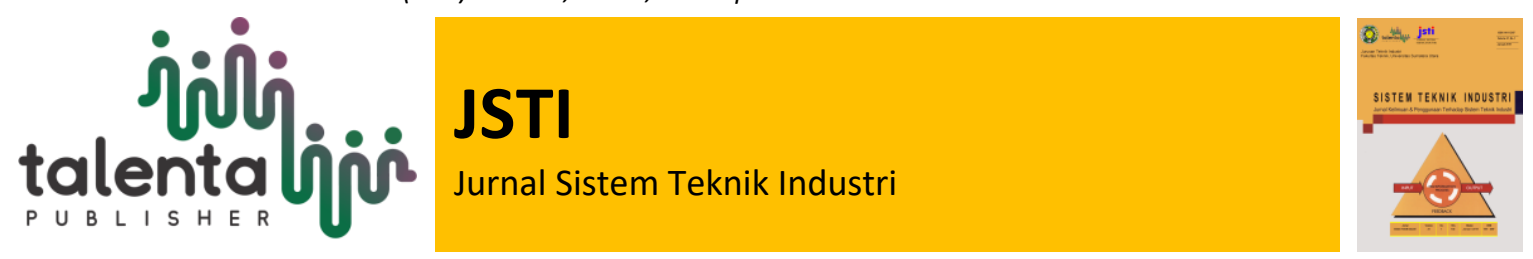

\title{
Penerapan 5s (Seiri, Seiton, Seiso, Seiketsu, Shitsuke) Sebagai Upaya Pengurangan Waste Pada Pt X
}

\author{
Dian Palupi Restuputri' ${ }^{1}$, Dika Wahyudin ${ }^{2}$ \\ 1,2 Fakultas Teknik, Universitas Muhammadiyah Malang
}

\begin{abstract}
Abstrak. PT X bergerak dalam bidang manufaktur yang bergerak di bidang pembuatan bahan bangunan. Pada bagian dalam area storage atau lebih dikenal dengan stockpile area terdapat banyak material yang merupakan bahan baku dan bahan bakar mesin. Pada area di luar area storage sering dijumpai perkakas atau alat kerja yang dimana alat teresebut tidak disimpan pada tempatnya dan tidak sesuai dengan kebutuhanya. Hal ini disebabkan oleh tidak adanya suatu tempat untuk menyimpan alat atau material tak terpakai di area storage berdasarkan fungsi dari alat dan material tersebut. Hal tersebut juga akan berdampak pada aktifitas produksi pekerja. Dari hasil Analisa 5s didapatkan budaya rapi merupakan budaya yang paling tinggi penyalanggunaanya dengan tingkat penyalanggunaan sebesar $34 \%$. Penyebab penyalahgunaan budaya $5 \mathrm{~S}$ disebabkan oleh tidak ada tempat penyimpanan sebesar $25 \%$. Kemudian diberikan solusi berupa desain khusus rak peralatan dan logo budaya $5 \mathrm{~s}$ yang diletakkan di dekat tempat peralatan dan permesinan
\end{abstract}

Kata Kunci: 5s, Kaizen, Waste, 5R, Continues Improvement

\begin{abstract}
P T X$ is engaged in manufacturing which is engaged in the manufacture of building materials. Inside the storage area, better known as the stockpile area, there are many materials which are raw materials and engine fuels. In areas outside the storage area, tools or work tools are often found where such equipment is not stored in place and is not in accordance with its needs. This is caused by the absence of a place to store tools or unused material in the storage area based on the functions of the tools and materials. This will also have an impact on workers' production activities. From the results of Analysis 5s, it was found that neat culture was the highest culture of distribution with a distribution rate of $34 \%$. The cause of misuse of $5 \mathrm{~S}$ culture is caused by no storage by $25 \%$. Then a solution was provided in the form of a special design of equipment rack and cultural logo 5 s placed near the equipment and machinery site.
\end{abstract}

Keywords: 5s, Kaizen, Waste, 5R, Continues Improvement

Received 9 January 2019 | Revised 23 January 2019| Accepted 23 January 2019

\section{Introduction}

Pendekatan proses produktivitas sering menekankan pada segi ekonomi saja sedangkan pada kenyataannya pendekatan produktivitas juga meliputi aspek - aspek non ekonomi, yang mana terkadang malah lebih besar peranannya dalam peningkatan produktivitas. Aspek- aspek non

*Corresponding author at: Jalan Raya Tlogomas 246 Malang

E-mail address: restuputri@umm.ac.id, dikawahyudin8@gmail.com 
ekonomi yang dimaksud, misalnya manajemen, organisasi, kualitas pekerjaan, kesehatan dan keselamatan kerja, motivasi kerja, dan lain-lain yang memiliki peran dalam mengorganisir individu atau kelompok yang berhubungan dalam kegiatan - kegiatan pada unit-unit untuk dapat bekerja lebih efektif dan efisien.

PT X bergerak dalam bidang manufaktur yang bergerak di bidang pembuatan bahan bangunan. Pada bagian dalam area storage atau lebih dikenal dengan stockpile area terdapat banyak material yang merupakan bahan baku dan bahan bakar mesin yang terdapat di PT X. Pada area di luar area storage sering dijumpai perkakas atau alat kerja yang dimana alat teresebut tidak disimpan pada tempatnya dan tidak sesuai dengan kebutuhanya contohnya adalah sekop yang tidak disimpan pada tempatnya ataupun material yang tak terpakai yang tidak disimpan pada tempatnya. Penyebabnya, ada beberapa dari operator yang tidak meletakkan peralatan pada tempatnya, dan meletakkan secara sembarangan, tidak adanya suatu tempat untuk menyimpan alat atau material tak terpakai di area storage berdasarkan fungsi dari alat dan material tersebut juga membuat peralatan menjadi berserakan. Hal ini tentunya menghambat produktivitasoperator dalam menyelesaikan pekerjaannya, karena jika peralatan tersebut akan di gunakan kembali maka dilakukan pencarian peralatan yang memakan waktu cukup lama. Dalam hal ini proses produksi akan mengalami penurunan kecepatan, sehingga bisa menyebabkan output yang sudah ditargetkan oleh perusahaan tidak bisa terpenuhi.

Beberapa penelitian telah menggunakan metode 5 s sebagai implementasi pengurangan waste misalnya yaitu Purwanggono, Ruminta, and Irawati (2014) yang menerapkan 5 s pada PT. PLN, Pakki, Soenoko, and Santoso (2014) penerapan 5s sebagai konsep six sigma, Margaretta (2015) penerapan 5s pada UMKM, serta Kurniawan (2013) yang menerapkan 5s pada Gudang Hypermart Surabaya, Jiménez, Romero, Domínguez, and del Mar Espinosa (2015) yang menerapkan 5s pada laboratorium jurusan Teknik industri di Spanyol dan Veres, Marian, Moica, and Al-Akel (2018) yang menerapkan 5s pada industry otomotif [1] [2] [3] [4] [5] [6].

Berdasar dari latar belakang diatas maka dibuatlah suatu analisa untuk proses identifikasi suatu permasalahan disebabkan oleh alat atau material yang tidak terpakai dan tidak diletakkan di tempat yang semestinya. Tujuan dari penelitian ini adalah untuk indentifikasi permasalahan menggunakan penerapan konsep 5S (Seiri, Seiton, Seiso, Seiketsu, Shitsuke), analisa penerapan metode 5S yang sudah ada sebelumnya tetapi belum dilakukan secara maksimal, pengelolaan data yang sudah didapatkan untuk mencari sebab akibat yang ada, serta akan memberikan saran untuk masalah tersebut. Penggunaan metode $5 \mathrm{~s}$ diharapkan dapat memperbaiki penataan, kebersihan dan kedisiplinan di tempat kerja guna meningkatkan produktifitas dan efisiensi pekerja.

\section{Landasan Teori}

Komitmen diperlukan pada suatu proses perbaikan kualitas agar perbaikan yang melibatkan secara seimbang antara sisi manusia dan sisi teknologi [7]. Kaizen adalah istilah dari bahasa Jepang pada konsep Continous Incremental Improvement. Kai yang memiliki arti perubahan dan 
Zen memiliki arti baik. Kaizen yaitu penyempurnaan dan berkesinambungan yang mana melibatkan semua orang. Kaizen merupakan suatu kesatuan pandangan yang yang komprehensif dan terintegrasi yang bertujuan untuk melaksanakan perbaikan secara terus-menerus. Pengertian falsafah $5 \mathrm{~S}$ yaitu:

a. Seiri adalah dengan menyisihkan barang yang dianggap tidak diperlukan dan barang yang dianggap tidak diperlukan di tempat kerja dibuang. Merupakan langkah awal dalam menjalankan budaya 5S, yaitu membuang/menyortir/ menyingkirkan barang-barang, file-file yang tidak digunakan lagi ke tempat pembuangan. Semua barang yang ada di lokasi kerja, hanyalah barang yang benar-benar dibutuhkan untuk aktivitas kerja. Tindakan dilakukan agar tempat penyimpanan menjadi lebih efisien, karena dipergunakan untuk menyimpan barang atau file yang memang penting dan dibutuhkan, serta bertujuan juga agar tempat kerja terlihat lebih rapi dan tidak berantakan. Keuntungan yang akan didapat dalam menerapkan Seiri (Ringkas-Sisih- Keteraturan-Pemilahan-Sort):

1. Kuantitatif:

a. Penghematan pemakaian ruangan.

b. Persediaan dan produk barang yang bermutu.

c. Kecepatan waktu pencarian barang/dokumen yang dibutuhkan.

2. Kualitatif:

a. Tempat kerja lebih aman.

b. Suasana kerja lebih nyaman.

c. Mencegah tempat/alat/bahan menjadi rusak lebih awal.

b. Seiton (susun) adalah dengan menata peralatan kerja yang digunakan dengan rapi dan menghilangkan kegiatan mencari agar alat-alat tersebut bisa dengan mudah ditemukan secara cepat. Setelah menyortir semua barang atau file yang tidak dipergunakan lagi, pastikan segala sesuatu harus diletakkan sesuai posisi yang ditetapkan, sehingga selalu siap digunakan pada saat diperlukan. Pastikan bahwa:

1. Setiap barang punya tempat.

2. Setiap tempat punya nama untuk barang tertentu.

3. Buat menjadi terorganisir dan sistematis.

4. Beri nama pada setiap tempat penyimpanan yang mudah diingat, dapat

5. menggunakan kode pada tempat penyimpan:

a. Bila berbentuk barang, berikan label dengan nama atau visual sebagai ciri khas.

b. Bila berbentuk file atau softcopy data, atur semua folder di komputer.

c. Pastikan agar mudah mengidentifikasi, saat file, barang ataupunbenda tersebut dibutuhkan, sehingga tidak perlu membuang banyak waktu untuk mencarinya.

c. Seiso adalah dengan memelihara kebersihan pada tempat kerja. Setelah menjadi rapi, langkah berikutnya adalah membersihkan tempat kerja, ruangan kerja, peralatan dan 
lingkungan kerja. Tumbuhkan pemikiran bahwa kebersihan merupakan hal yang fital dalam kehidupan, jika kita tidak menjaga kebersihan, lingkungan akan menjadi kotor dan menjadi faktor utama terjangkitnya penyakit tidak nyaman. Menyebabkan berkurangnya produktivitas dan berakibat banyak kerugian. Lakukanlah pembersihan harian, pemeriksaan kebersihan dan pemeliharaan kebersihan.

Seiketsu adalah dengan mempertahankan seiri, seiton, dan seiso agar proses tersebut bisa berlangsung secara terus-menerus. Tahap ini adalah tahap yang sukar. Untuk menjaga ketiga tahap yang sudah dijalankan sebelumnya secara rutin. Tahap ini dapat juga disebut tahap perawatan, merupakan standarisasi dan konsistensi dari masing-masing individu untuk melakukan tahapan-tahapan sebelumnya. Membuat standarisasi dan semua individu harus patuh pada standar yang telah ditentukan. Dapat dimotivasi dengan memberikan hadiah atau hukuman.

d. Setsuke adalah suatu bentuk kedisiplinan yang mana hal tersebut menjadi kebiasaan, sehingga para pekerja menjadi biasa mematuhi peraturan dan dilaksanakan penyuluhan kepada para pekerja agar dapat bekerja dengan profesional. Pemeliharaan kedisiplinan pribadi meliputi suatu kebiasaan dan pemeliharaan program $5 \mathrm{~S}$ yang sudah berjalan. Bila berada pada posisi sebagai atasan, buatlah standarisasi $5 \mathrm{~S}$ serta berikan pelatihan $5 \mathrm{~S}$, agar seluruh karyawan perusahaan dapat mengerti akan kegunaan dari 5S sebagai dasar kemajuan perusahaan, karena dengan menerapkan $5 \mathrm{~S}$ yang praktis dan ringkas bertujuan pada efisiensi, pelayanan yang baik, keamanan bekerja serta peningkatan produktivitas dan profit.

Manfaat dari penerapan budaya 5R (5S) di tempat kerja yaitu :

a. Produktivitas menjadi lebih meningkat disebabkan pengaturan di tempat kerja yang lebih efisien.

b. Kenyamanan menjadi lebih meningkat disebabkan pada tempat kerja menjadi selalu bersih serta lebih luas dan lapang.

c. Bahaya yang ada di tempat kerja menjadi lebih berkurang hal ini disebabkan kualitas pada tempat kerja menjadi lebih baik.

d. Penghematan bertambah hal ini dikarenakan dapat pemborosan di berbagai tempat kerja dapat dikurangi.

Konsep 5R / 5S yaitu merupakan proses perubahan sikap dengan cara menerapkan aspek penataan, kebersihan dan kedisiplinan di tempat kerja. Dengan menerapkan prinsip "A place for everything and every thing in its place" maka setiap anggota organisasi dibiasakan bekerja dalam lingkungan kerja dengan standar tempat yang jelas [8].

Pada konsep 5R / 5S juga bagian dari konsep kaizen yang memiliki arti penyempurnaan secara berkesinambungan pada kehidupan pribadi, kehidupan di keluarga, lingkungan sosial ataupun juga tempat kerja [9]. Konsep 5R/5S juga mengenai budaya bagaimana pekerja dapat 
memperlakukan tempat kerja dengan benar. Jika pada tempat kerja dapat tersusun dengan rapi, bersih, tertib sehingga kemudahan bekerja perorangan bisa diciptakan. Hal ini berarti pada kemudahan bekerja dapat dicapai empat bidang sasaran pokok industri yang meliputi :

- $\quad$ Efisisensi Kerja

- $\quad$ Produktifitas dalam bekerja

- Kualitas dalam bekerja

- $\quad$ Keselamatan dalam bekerja yang bisa lebih mudah dipenuhi.

Pemenuhan dalam saran pokok ini adalah syarat pada industri dalam bertumbuh kembang sehingga manfaatnya dapat dinikmati bukan bagi perusahaan saja, tetapi juga bagi pekerja. Untuk kegiatan 5S sebelum dimulai, ada hal yang harus dilakukan pertama kali yaitu dengan mengambil foto di tempat kerja. Hal ini akan memiliki manfaat sebagai perbandingan dengan keadaan sebelumnya jika konsep 5R/5S dapat dikerjakan sepenuhnya [8].

\section{Metode Penelitian}

Penelitian ini dimulai dari mengumpulkan data - data dengan proses observasi, wawancara dan dokumentasi. Kemudian membandingkan data tersebut dengan literatur yang ada. Data tersebut kemudian diseleksi berdasar tingkat kepentingannya mulai dari yang tertinggi hingga terendah. Hasilnya kemudian akan ditarik kesimpulan dan diberikan solusi dari permasalahan tersebut. Langkah- langkah dapat dilihat pada gambar 1 berikut : 


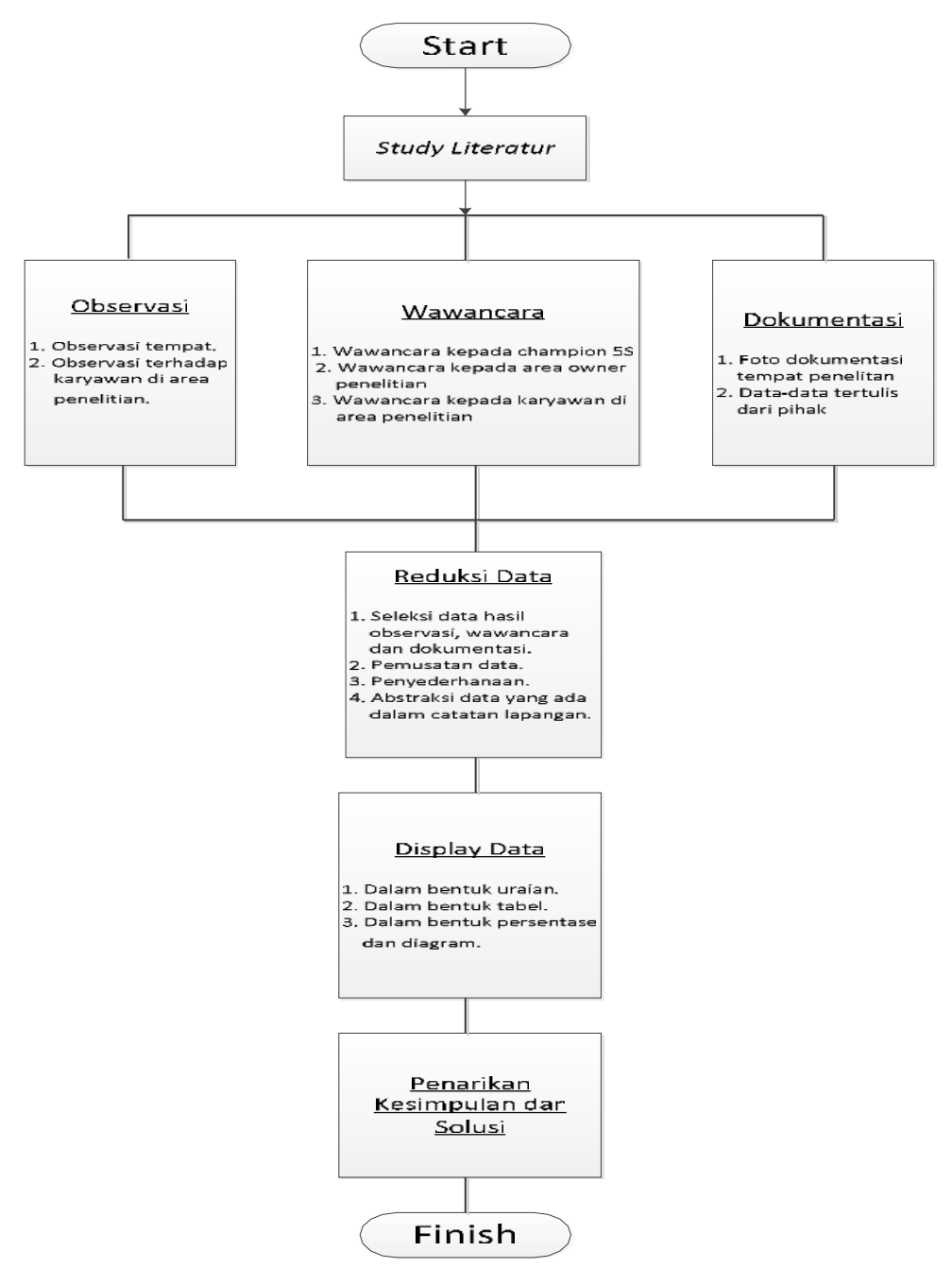

Figure 1 Metode Penelitian

\section{Pembahasan}

Indikator merupakan suatu objek yang digunakan untuk memberikan keterangan. Pada penelitian kali ini, objek yang diteliti berhubungan dengan budaya 5S/5R di area Material Storage bisa dilihat di tabel 1 .

Table 1 Tabel Indikator 5s

\begin{tabular}{|c|c|c|}
\hline No & Jenis 5s & $\begin{array}{c}\text { Objek Yang Diteliti / } \\
\text { Indikator }\end{array}$ \\
\hline 1 & Ringkas & $\begin{array}{ll}\text { 1. } & \text { APAR } \\
\text { 2. } & \text { Hydrosol } \\
\text { 3. } & \text { Display } \\
\text { 4. } & \text { Material } \\
\text { 5. } & \text { Sodium Silica } \\
\text { 6. } & \text { Batang Besi } \\
\text { 7. } & \text { Hydrant } \\
\text { 8. } & \text { Perkakas }\end{array}$ \\
\hline
\end{tabular}


Table 1 Tabel Indikator 5s

\begin{tabular}{|c|c|c|}
\hline No & Jenis 5s & $\begin{array}{c}\text { Objek Yang Diteliti / } \\
\text { Indikator }\end{array}$ \\
\hline 2 & Rapi & $\begin{array}{l}\text { 1. APAR } \\
\text { 2. Hydrosol } \\
\text { 3. APD } \\
\text { 4. Display } \\
\text { 5. Tempat Sampah } \\
\text { 6. Sodium Silica } \\
\text { 7. Batang Besi } \\
\text { 8. Jurigen } \\
\text { 9. Hydrant } \\
\text { 10. Engsel } \\
\text { 11. Jumbo Bag } \\
\text { 12. Kabel } \\
\text { 13. Perkakas } \\
\text { 14. Pallet } \\
\text { 15. Kawat }\end{array}$ \\
\hline 3 & Resik & $\begin{array}{l}\text { 1. Hydrosol } \\
\text { 2. Display } \\
\text { 3. Tempat Sampah } \\
\text { 4. Material } \\
\text { 5. Sodium Silica } \\
\text { 6. Batang Besi } \\
\text { 7. Jurigen } \\
\text { 8. Jumbo Bag } \\
\text { 9. Rumput Kering } \\
\text { 10. Pallet } \\
\text { 11. Kawat }\end{array}$ \\
\hline 4 & Rawat & 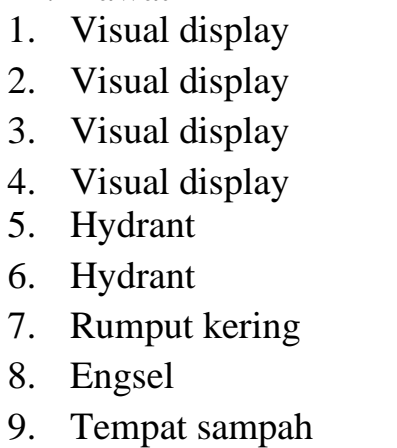 \\
\hline 5 & Rajin & 1. APAR \\
\hline & h Objek & 37 \\
\hline
\end{tabular}

Perhitungan Indikator :

$$
\frac{\text { Indikator dalam setiap budaya }}{\text { Indikator Keseluruhan }} \times 100 \%
$$

Ringkas : $\frac{8}{37} \times 100 \%=18 \%$

Rapi $\quad: \frac{15}{37} \times 100 \%=34 \%$ 
Resik : $\frac{11}{37} \times 100 \%=25 \%$

Rawat : $\frac{9}{37} \times 100 \%=21 \%$

Rajin $: \frac{1}{37} \times 100 \%=2 \%$

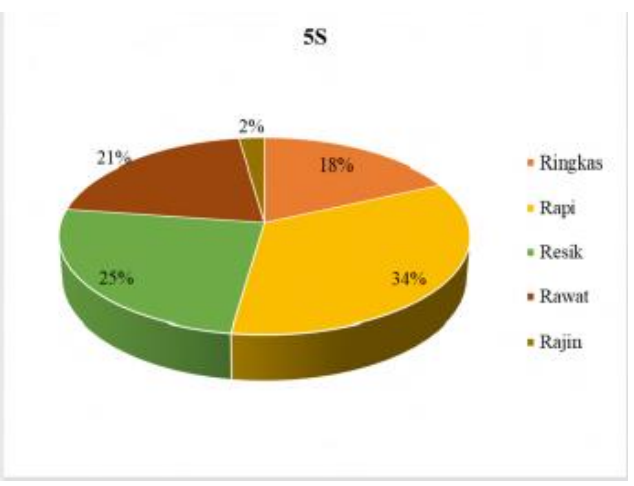

Figure 2 Persentase Indikator 5S

Dilihat dari prosesntase indikator gambar 1, budaya rapi merupakan budaya yang paling tinggi penyalanggunaanya dengan tingkat penyalanggunaan sebesar $34 \%$ serta budaya rajin merupakan budaya yang paling rendah penyalanggunaanya dengan tingkat penyalahgunaan sebesar $2 \%$.

Akumulasi Penyebab 5S merupakan rangkuman penyebab penyalahgunaan budaya 5S yang dimana didapat dari penyebab ke-29 masalah kemudian diakumulasikan dan dikelompokan sesuai jenis penyebabnya. Setelah akumulasi, langkah selanjutnya adalah membuat persentase dari akumulasi tersebut dengan tujuan untuk menetukan prioritas solusi.

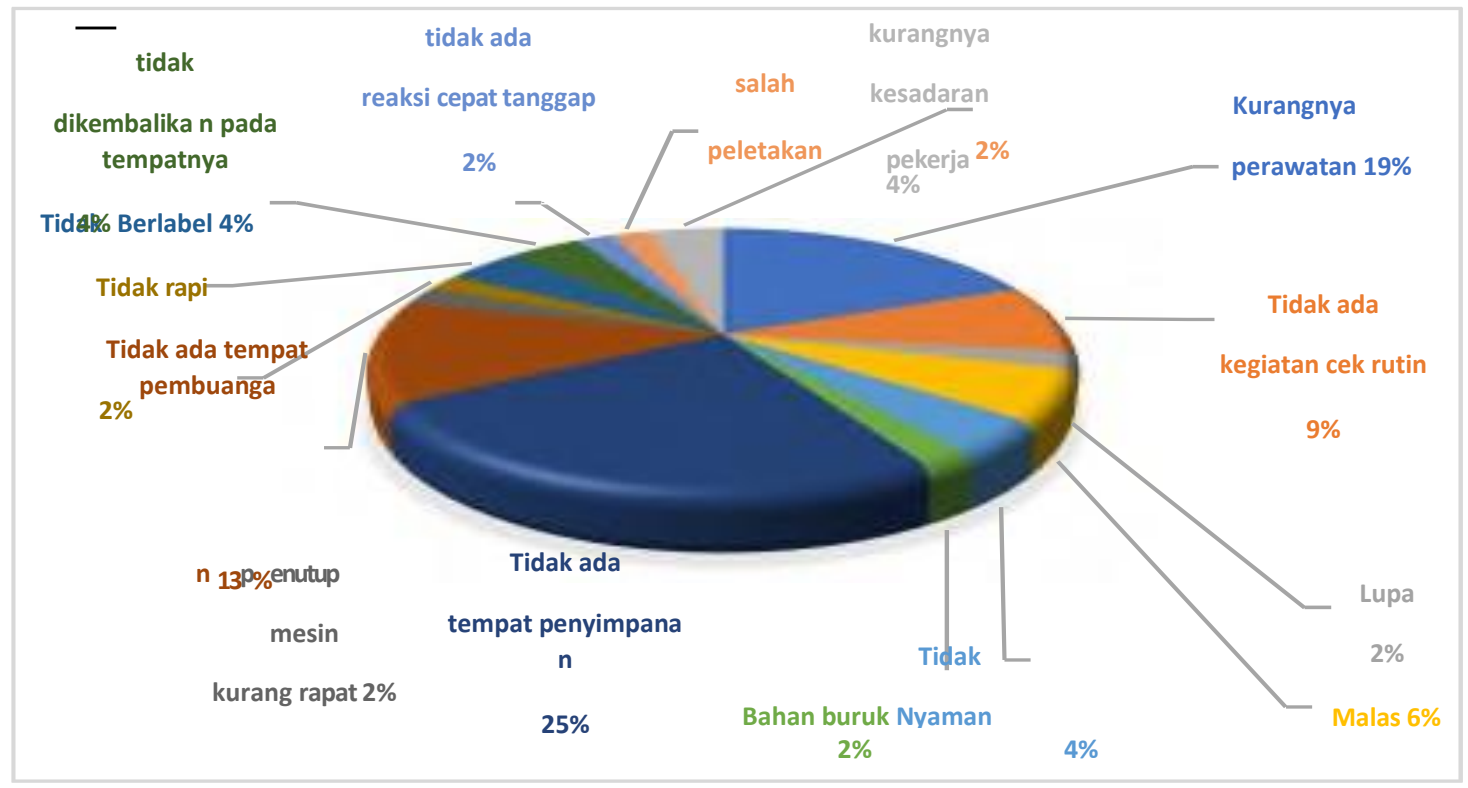

Figure 3 Persentase Akumulasi Penyebab 5S

Dapat dilihat pada gambar 2 dari indikator dan penyebab, rapi dan tidak ada tempat penyimpanan merupakan sumber utama permasalahan terbesar. Faktanya memang di area storage tidak ada tempat untuk menyimpan alat atau bahan yang tidak dipakai berdasarkan 
golonganya. Hal ini dapat memicu penurunan produktifitas dan efisiensi pekerja karena jika terjadi suatu hal dan memerlukan alat atau bahan tertentu maka akan lebih cepat di perbaiki. Contoh saat terjadi error pada mesin karena ada material yang tersangkut, maka pekerja yang dalam shift tersebut bisa menggunakan alat seperti sekop atau lainya untuk mengambil material yang tersangkut. Hal tersebut sering kali terjadi mengingat PT X adalah perusahaan yang memproduksi bahan bangunan seperti semen yang dimana menggunakan material besar seperti batu kapur, tanah liat, batu bara dan lainya. Mesin yang digunakan seringkali melemparkan material tersebut ke arah roda belt coveyer sehingga dapat menyumbat roda tersebut.

Hydrant disini sering disalah gunakan sebagai penyemprot air untuk mengurangi debu atau panas yang dihasilkan batubara di stockpile. Jika baturbara tergolong porsi besar menggunakan hydrant namun jika sedikit menggunakan mobil tangki.

Penyemprotan dengan tanki menurut saya tidak efisien karena memakan biaya serta waktu karena harus mengisi air. Solusinya adalah dengan menyediakan hydrant khusus untuk menyemprotkan air untuk mengurangi debu atau panas yang dihasilkan batu bara Tempat sampah di area storage sangatalah minim, hanya ada 3-5/storage yang dimana storage tersebut sangatah luas dan cukup untuk meniympan 32 ribu ton material. Penambahan tempat sampah sangatlah dibutuhkan

Di area storage juga minim area penyimpanan perkakas, dimana perkakas disini rata rata penyimpanannya pribadi oleh masing-masing karyawan sehingga saya kesusuhan menemukan perkakas yang terlihat, namun hal itu sangat bertentangan dengan penerapana $5 \mathrm{R} / 5 \mathrm{~S}$ yang dimana jika penerapanya bisa maksimal akan menambah efisiensi, produktifitas, kualitas dan keselamatan kerja. Perlu adanya penambahan rak-rak untuk menyimpan perkakas atau alat di area storage jika terjadi sesuatu hal, pekerja akan lebih mudah menemukan alat atau perkakas yang dibuthkan. Masalah housekeeping disini juga cukup rumit, karean sistem antrian menjadi sistem yang diterapkan dimana area yang mempunyai area yang kotor lebih banyak akan mendapat prioritas. Hal ini bisa menjadi permasalahan karena setiap area wajib mempunyai standar kebersihan, kerapian, perawatan tertentu sehingga hal yang tidak diingkan tidak terjadi Untuk perawatan alat disini cukup bagus karena tiap rolling shift selalu melakukan check alat, material serta area.

Solusi dari permasalahan 5 s adalah sebagai berikut :

a. Evaluasi secara berkesinambungan dari manajemen dari setiap unit, serta diadakan lomba untuk 5R.

b. Evaluasi tempat untuk proses perpindahan barang agar semakin cepat serta mudah diantara unit-unit.

c. Membuat serta penambahan dari rak, troli, box, nampan

d. Pekerja harus dapat mengerti dan mengaplikasikan 5R untuk kemajuan perusahaan, diharapkan $5 \mathrm{R}$ bisa membuat perubahan pada pola pikir setiap pekerja. 
e. Melakukan rapat setiap pagi bagi para pekerja (briefing) dengan harapan agar pekerja dapat mengerti dan memahami tentang 5R.

f. Pembaharuan dan penambahan fasilitas penunjang budaya $5 \mathrm{R} / 5 \mathrm{~S}$

g. Penambahan tim yang bertugas untuk inspeksi budaya 5R/5S yang dilakukan setiap hari.

h. Lebih meningkatkan perawatan dan cek fasilitas penunjang budaya $5 \mathrm{R} / 5 \mathrm{~S}$

i. Solusi Permasalahan khusus diberikan jika suatu masalah tersebut hanya cocok untuk beberapa masalah. Dalam masalah budaya 5S di PT X, masih banyak kendala/masalah yang memerlukan tindakan khusus untuk mengatasainya seperti penambahan dan pembaharuan fasilitas karena sebelumnya memang tidak ada fasilitas penunjang budaya 5R/5S. Dalam hal penelitian ini, pengadaan rak/tempat menyimpan dan label sangat diperlukan karena masih banyak alat/material atau lainya yang belum memiliki rak/tempat khusus.

j. Penambahan Berupa rak yang dilengkapi kode barang, label barang, fungsi barang dan nama pemakai terakhir. Ada 2 jenis rak yang akan digunakan yaitu rak untuk menyimpan alat dan alat untuk menyimpan barang yang tidak terpakai. Rak pertama berguna untuk menyimpanan barang yang berukuran sedang atau kecil seperti jurigen, kawat, kabel atau lainya. Rak tersebut juga dilengkapi dengan batas sediaan maksimum dan minimum untuk memudahkan pekerja untuk dapat mengetahui jumlah minimum dan maksimum secara cepat tanpa harus membaca setiap jumlah yang ditulis. Rak ini akan di tempatkan di tempat yang mempunyai mesin seperti Harrow machine, Reclaimer karena mesin-mesin tersebut membutuhkan oli, kawat atau lainya.. Rak kedua berguna untuk menyimpanan barang yang berukuran sedang atau kecil seperti jurigen, kawat, kabel atau lainya. Rak tersebut juga dilengkapi dengan batas sediaan maksimum dan minimum untuk memudahkan pekerja untuk dapat mengetahui jumlah minimum dan maksimum secara cepat tanpa harus membaca setiap jumlah yang ditulis. Rak ini akan di tempatkan di tempat yang mempunyai mesin seperti Harrow machine, Reclaimer karena mesin-mesin tersebut membutuhkan oli, kawat atau lainya. Hal yang perlu dilakukan itu misalnya memisahkan bahanbahan yang dibutuhkan dengan yang tidak dibutuhkan, bahan diatur sesuai dengan yang digunakan harus diletakkan di dekat tempat penggunaannya, begitu juga dengan pelat kode tempat, pelat kode barang, dan garis-garis penunjuk jumlah [10]. 


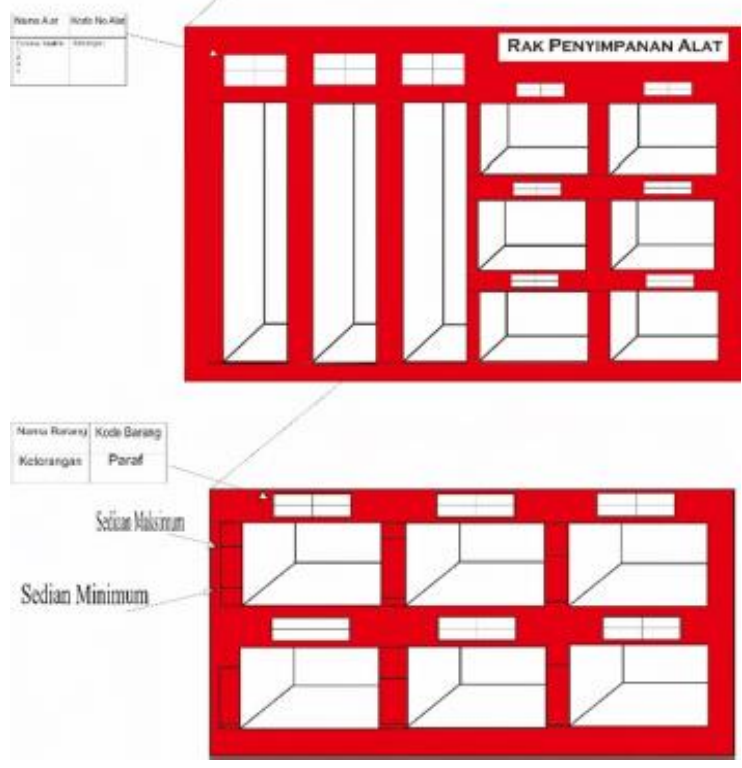

Figure 4 Usulan Rak Penyimpanan Barang

k. Penambahan Display bertujuan untuk menekankan bahwa spot tersebut sangatlah rawan terjadi tidak diterapkanya budaya 5R/5S. Setiap logo mewakili 5 pilar budaya 5R/5S sehingga setiap logo memiliki perbedaan dari segi warna, segi bentuk dan segi tujuan. Logo/Display budaya 5R/5S dapat diletakkan di daerah yang rawan seperti area dekat dengan mesin dan lainya dengan cara logo dari plat besi yang sudah dibentuk dan diwarnai menyerupai display. Penambahan logo sangatlah penting karena dengan adanya logo karyawan dapat lebih berhati-hati dalam melakaukan pekerjaanya.

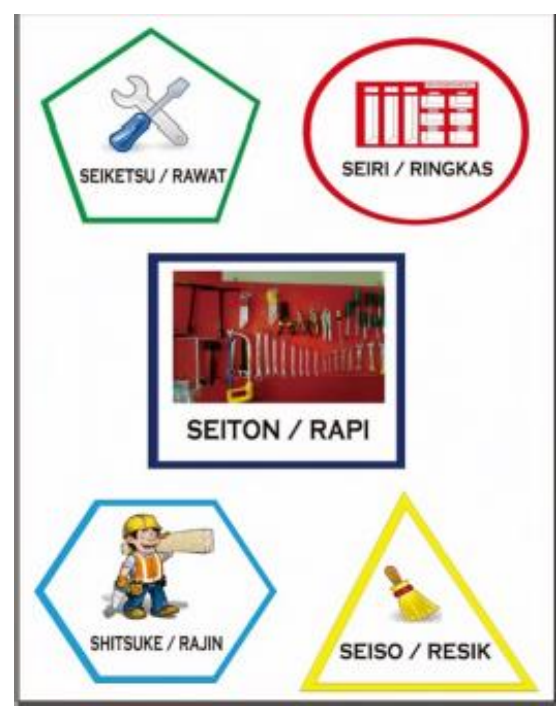

Figure 5 Usulan Logo Budaya 5S 


\section{Kesimpulan}

Adapun kesimpulan yang diperoleh dari penilitian ini adalah sebagai berikut.

1. $\mathrm{PT} X$ telah menerapkan budaya $5 \mathrm{R} / 5 \mathrm{~S}$ di area perusahaan. Tetapi penerapan budaya 5S/5R di PT X masih banyak terkendala Internal dan Eksternal seperti kesadaran karyawan akan budaya 5R/5S, kurangnya fasilitas yang menunjang dan lain sebagainya.

2. Adapun tindakan pengendalian akan kendala budaya $5 \mathrm{R} / 5 \mathrm{~S}$ yang dilakukan $\mathrm{X}$ antara lain :

a. Pengawasan karyawan dalam penerapan budaya $5 \mathrm{R} / 5 \mathrm{~S}$

b. Induction tentang budaya $5 \mathrm{R} / 5 \mathrm{~S}$ yang dilaksanakan oleh departement $\mathrm{K} 3$

c. Adanya pengawasan lapangan yang dipimpin oleh area owner selaku penanggung jawab budaya $5 \mathrm{R} / 5 \mathrm{~S}$ di setiap area.

d. Adanya Housekeeping yang merupakan aktifitas gotong royong untuk membersihkan area yang jadwalnya sudah diatur.

\section{REFERENSI}

[1] B. Purwanggono, R. Ruminta and S. Irawati, "Analisis Faktor-faktor yang Memengaruhi Motivasi Karyawan dalam Menerapkan Budaya Kerja 5s (Studi Kasus pada Karyawanpt. Pln (Persero) P3jb App Semarang)," Prosiding SNATIF, pp. 57-68, 2014.

[2] G. Pakki, R. Soenoko and P. B. Santoso, "Usulan Penerapan Metode Six Sigma Untuk Meningkatkan Kualitas Klongsong (Studi Kasus Industri Senjata)," Journal of Engineering and Management in Industrial System, p. 2, 2014.

[3] Y. Margaretta, "Penerapan 5S pada UMKM Kerajinan Gerabah di Daerah Istimewa Yogyakarta," UAJY, 2015.

[4] H. Kurniawan, "Studi Deskriptif Manajemen Kualitas dengan Metode 5S di Gudang Hypermarket X Surabaya," CALYPTRA, vol. 2, no. 2, pp. 1-20, 2013.

[5] M. Jiménez, L. Romero, M. Domínguez and del Mar , "5S Methodology Implementation in the Laboratories of An Industrial Engineering University School," Safety science, vol. 78, pp. 163-172, 2015.

[6] C. Veres, L. Marian, S. Moica and K. Al- Akel, "Case Study Concerning 5S Method Impact in An Automotive Company," Procedia Manufacturing, vol. 22, pp. 900- 905, 2018.

[7] V. Gaspersz and A. Fortana, Lean Six Sigma for Manufacturing and Service Industries, Jakarta: PT. Gramedia Pustaka Utama, 2007.

[8] H. Hirano, 5S for Operators: 5 Pillars of the Visual Workplace, Productivity press, 1996. 
[9] M. Imai, Kaizen: The Key to Japan's Competitiveness, NY: Random House, 1986.

[10] Y. Monden and B. Talbot, Cost Reduction Systems: Target Costing and Kaizen Costing, 1995. 